\title{
Priming with Age Stereotypes Influences the Performance of Elderly Workers
}

\author{
Christine Kirchner, Ina Völker, Otmar Leo Bock \\ German Sport University Cologne, Institute of Physiology and Anatomy, Cologne, Germany \\ Email: c.kirchner@dshs-koeln.de
}

Received 6 January 2015; accepted 26 January 2015; published 29 January 2015

Copyright (C) 2015 by authors and Scientific Research Publishing Inc.

This work is licensed under the Creative Commons Attribution International License (CC BY). http://creativecommons.org/licenses/by/4.0/

c) (i) Open Access

\begin{abstract}
Studies have shown that priming with negative age stereotypes can degrade the performance of older adults on typical laboratory tasks. Here we evaluate whether priming with positive age stereotypes can improve performance on an ecologically valid task, modelled after the subjects' duties at work. Twenty healthy employees (age: $\emptyset \mathbf{5 2 . 7 5}$ years; SD $=9.45$ ) from the receiving department of a wholesale company were primed with the scrambled sentence task. The experimental group $(n=10)$ was primed with positive age stereotypes such as "wise". In the control group $(n=10)$ no age stereotypes were presented. Both groups were subsequently tested with a delivery-verification task, in which the contents of a parcel had to be checked against an invoice. The experimental group completed the verification task within 4.31 minutes $(S D=2.22)$, and the control group within 7.18 minutes $(S D=2.12)$. The difference was statistically significant $(t(18)=$ 2.8; $p<0.05$ ). Positive supraliminal priming appears to be a promising technique to enhance the job-related performance of elderly employees.
\end{abstract}

\section{Keywords}

Stereotypes, Priming, Aging, Job Performance, Ecological Validity

\section{Introduction}

As our workforce grows older due to demographic change, it becomes increasingly important to maintain the working efficiency of older employees. Policies and procedures should target not only the age-related decay of biological and psychological functions, but also the impact of societal attitudes towards the elderly. Since people behave in ways that are consistent with prevailing societal stereotypes (Wheeler \& Petty, 2001), it stands to reason that elderly persons act in accordance with the largely negative preconceptions about old age (Kite, Stockdale, Whitley, \& Johnson, 2005) and thus perform less well than they would otherwise. Experimental evidence 
for such a self-fulfilling prophecy comes from studies that induce positive or negative attitudes towards old age by means of priming. In this approach, memory contents are activated by semantic or figurative cues that either are presented at full awareness (explicit priming), are disguised by integration into another task (supraliminal priming), or are flashed so briefly that conscious processing is excluded (subliminal priming); it is yet unknown which of these methods is most effective (Horton, Baker, Pearce, \& Deakin, 2008).

Studies using the subliminal method observed improvements following positive age primes and impairments following negative age primes on performance measures as different as cardiovascular function (Levy, Hausdorff, Hencke, \& Wei, 2000), handwriting (Levy, 2000), locomotion (Hausdorff, Levy, \& Wei, 1999), sensorimotor plasticity (Bock, Grigorova, \& Ilieva, 2013), cognition (Hess, Hinson, \& Statham, 2004) and the will to live (Levy, Ashman, \& Dror, 2000). Other studies used the supraliminal "scrambled sentence task" (Bargh, Chen, \& Burrows, 1996): under the pretext of a language proficiency experiment, subjects are instructed to form meaningful sentences from lists of five words, where unbeknownst to them one of the five words represents an age stereotype. This priming method was found to affect subjects' performance on a walking (Bargh et al., 1996), a driving simulator (Branaghan \& Gray, 2010), and a memory-recall task (Hess et al., 2004).

In light of these findings, it is tempting to speculate that positive age primes might also improve on-the-job performance of older workers, and thus help society to meet the challenge of an aging workforce. However, it remains to be shown that the effects of priming, previously documented with standardized laboratory tasks, extend to natural behavior such as duties at work. In fact, laboratory and everyday-like conditions can differ dramatically with respect to motor behavior (Bock \& Züll, 2013), to age-related motor deficits (Bock \& Beurskens, 2010; Bock \& Steinberg, 2012), and thus possibly also to effects of priming on those deficits. We therefore decided to design a task that closely mimics delivery verification in a commercial goods receiving department, and to test the effects of priming on the employees of such a department, i.e., on persons who perform similar tasks as part of their daily routine. As a corollary, we wanted to find out whether priming affects not only on the subsequent task performance, but also on the overall appraisal of one's own job competence. To this end, we asked the primed subjects to complete an established occupational self-efficacy scale.

\section{Methods}

\subsection{Participants}

Twenty healthy older employees of a wholesale market (mean $24.11 \pm 9.89$ years professional experience in the goods receiving department) participated. They were randomly assigned either to a positive ( 3 men; 7 women, $\varnothing$ 54.6 years, $\mathrm{SD}=6.72$ ) or to a neutral group ( 2 men; 8 women, $\varnothing 50.9$ years, $\mathrm{SD}=11.65$ ). All participants were healthy by self-report (questionnaire concerning actual human condition and medication), had normal or corrected to normal vision, gave informed consent, and were fluent in reading and speaking the German language. The study was approved by the Ethics Committee of the German Sport University.

\subsection{Task Design and Materials}

Experimental procedures consisted of three steps, as illustrated in Figure 1. Testing took place directly at the participants' workplace.

In the first step, the scrambled sentence task was administered as described by Bargh et al. (1996). Twenty sets of five words each were printed on paper cards with Arial 20 font. The cards were sequentially presented, and subjects were asked to form a meaningful sentence with four words from each card, without modifying any word. For example, a card with the words "DIGNIFIED; Crude; Friar; The; Is" could be used to create the sentence “THE FRIAR IS DIGNIFIED”. Subjects were asked to write the sentence on a sheet of paper and the next card was then shown, allowing a maximum of fifteen minutes per all cards. One subject out of the neutral group could not meet that limit and was excluded and replaced. For subjects in the positive group, each card included one word reflecting a positive stereotypes about old age (“ACCOMPLISHED, ACTIVE, ALERT, DIGNIFIED, DISTINGUISHED, EXPERIENCE, GENEROUS, INDEPENDENCE, INSIGHTFUL, INTERESTING, KINDNESS, KNOWLEDGEABLE, LOVING, PATIENCE, PRIDE, RESPECTED, SOCIABLE, SUCCESSFUL, UNDERSTANDING, WISE”) whereas for subjects in the neutral group, age stereotypes were absent.

As a second step, the BSW-Scale on occupational self-efficacy (Abele, Stief, \& Andrä, 2000) was administered. This scale consists of six questions to be answered on a four-level Likert scale (cf. Figure 1). The BSW- 


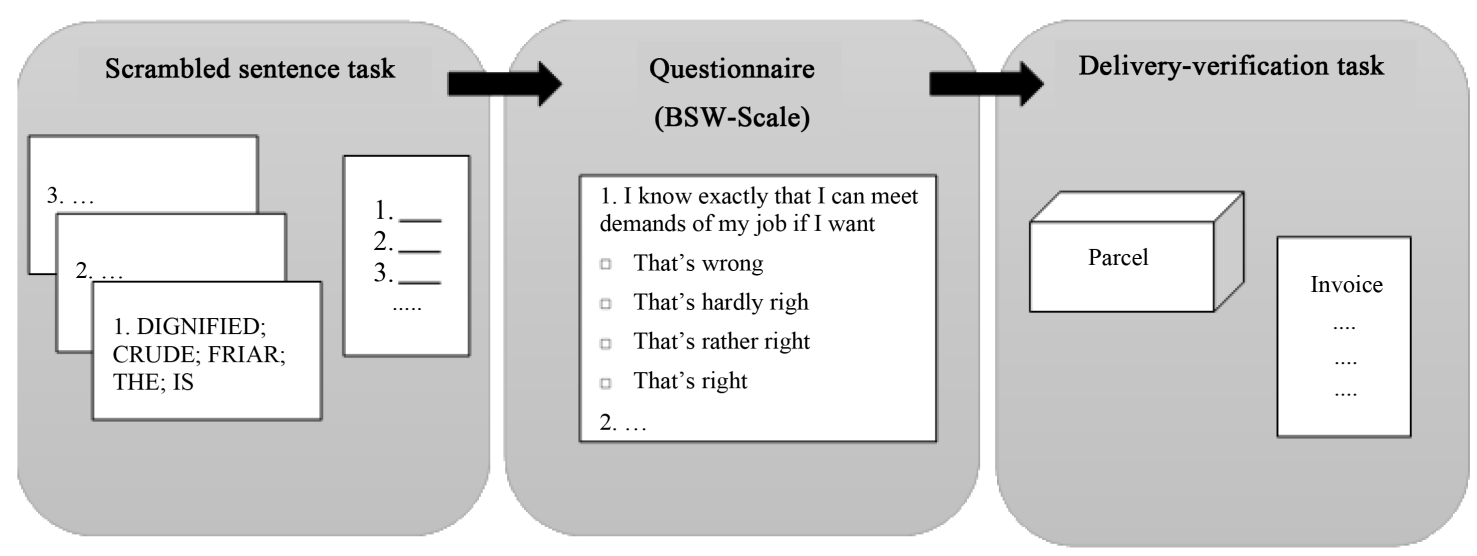

Figure 1. Workflow of the experiment.

Scale is an upgrade of the general skill expectations scale (Schwarzer \& Jerusalem, 1995) which focuses on job specific terms.

As a third step, subjects were given a delivery-verification task. They had to check whether the contents of a parcel corresponded with an invoice comprised of seventeen articles. The test persons had to mark fault or correctness with a pen on the invoice. Mistakes could occur when an item was in the parcel but not on the invoice, or when an item was on the invoice but not in the parcel. Dependent variables in this task were "duration", i.e., the time needed to complete the task, and "mistakes", i.e., the number of items erroneously marked on the invoice as present or missing.

After finishing the experimental procedure participants were asked three questions according to Hess et al. (2004) to check their awareness of the nature of the study ("What do you think the purpose of the study was?”; "How could the words in the scrambled sentence task have affected your behavior?"; "Did you notice any relation between the words in the scrambled sentence task and the concept of age?”).

\subsection{Statistical Analysis}

Data from the positive and the control group were compared with $t$-tests for independent means, and with an analysis of covariance that used the factor "group" (positive, neutral), the covariates "mistakes" and "BSWscore”, as well as the dependent variable "duration".

\section{Results}

Figure 2 shows the means of either group for the dependent variables "BSW-score”, "duration" and "mistakes". $t$-tests yielded statistical significance only for "duration" $(t(18)=2.8, p<0.001, p<0.05$ after Bonferroni-Holm adjustment for multiple comparisons), not for "mistakes" and "BSW-score" (both $p>0.05$ ).

The analysis of covariance produced no significant covariates (both $p<0.05$ ), and "duration" remained significant $(\mathrm{F}(1,16)=5.03, p<0.005)$.

\section{Discussion}

The present study documents for the first time that priming with positive age stereotypes is beneficial for the performance of elderly workers on a task modeled after real duties at work. It thus extends earlier research that used age stereotypes and typical laboratory tasks. The latter distinction is important, since motor performance on laboratory tasks is dramatically different from that on real-life like tasks-even if the biomechanical constraints are identical (Bock \& Hagemann, 2010; Bock \& Beurskens, 2011; Bock et al., 2013).

Interestingly, the benefits of positive priming emerged only with respect to task duration: the positive group was about 38\% faster than the neutral group. We attribute the absence of benefits with respect to task mistakes to the realism of our delivery-verification task: it is not acceptable for receiving-department workers to commit verification errors on the job, elderly employees therefore likely sacrifice speed to maintain accuracy, and benefits of priming thus could only manifest in speed. The analysis of covariance confirmed that those benefits can't 

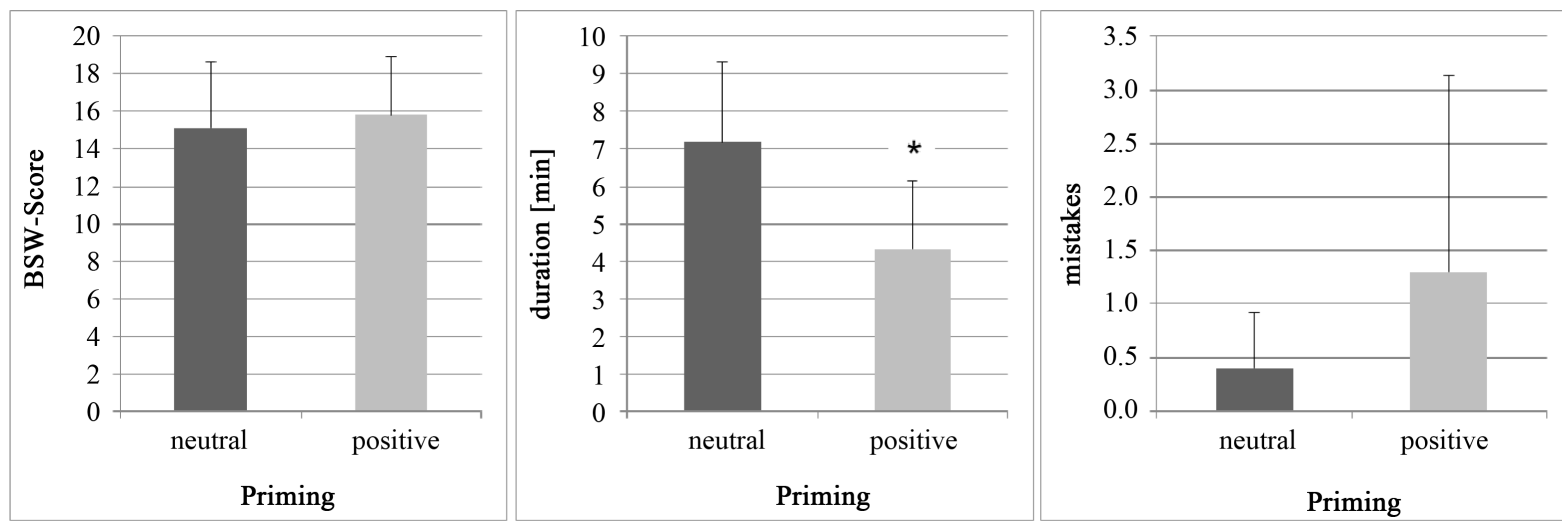

Figure 2. Means of the dependent variables in group neutral and positive; error bars indicate standard deviations.

be attributed to spurious effects of the other two variables.

The absence of priming benefits with respect to the BSW-scores might indicate that self-efficacy is immune to priming, or that it needs a higher dose of priming than provided in our study, or that the sample size of $n=10$ was too small to ascertain a priming benefit. However, we favor a fourth interpretation: the BSW-Scale assesses self-efficacy of one's whole past working life, not just of the momentary situation. If so, the present data would indicate that priming with positive age stereotypes has anterograde effects on the upcoming task, but no substantive retrograde effects on the preceding years at work. It would be desirable to scrutinize this view with a variant of the BSW-Scale that specifically addresses self-efficacy with respect to the upcoming task rather than with respect to one's own working life in general.

\section{Conclusion}

We conclude that priming is a method to activate age stereotypes and thus affect performance in a positive way. The results indicate that priming with positive age stereotypes-e.g. through posters, messages and speeches with interspersed relevant words - might help older employees to achieve a higher work efficiency and thus also a higher job satisfaction.

\section{References}

Abele, A. E., Stief, M., \& Andrä, M. S. (2000). Zur ökonomischen Erfassung beruflicher SelbstwirksamkeitserwartungenNeukonstruktion einer BSW-Skala. Zeitschrift für Arbeits- und Organisationspsychologie, 44, 145-151. http://dx.doi.org/10.1026//0932-4089.44.3.145

Bargh, J. A., Chen, M., \& Burrows, L. (1996). Direct Effects of Trait Construct and Stereotype Activation on Action. Journal of Personality and Social Psychology, 71, 230-244. http://dx.doi.org/10.1037/0022-3514.71.2.230

Bock, O., \& Beurskens, R. (2010). Changes of Locomotion in Old Age Depend on Task Setting. Gait \& Posture, 32, 645649. http://dx.doi.org/10.1016/j.gaitpost.2010.09.009

Bock, O., \& Beurskens, R. (2011). Effects of a Visual Distracter Task on the Gait of Elderly versus Young Persons. Current Gerontology and Geriatrics Research, 2010, Article ID: 651718.

Bock, O., \& Hagemann, A. (2010). An Experimental Paradigm to Compare Motor Performance under Laboratory and under Everyday-Like Conditions. Journal of Neuroscience Methods, 193, 24-28.

http://dx.doi.org/10.1016/j.jneumeth.2010.08.005

Bock, O., \& Steinberg, F. (2012). Age-Related Deficits of Manual Grasping in a Laboratory versus in an Everyday-Like Context. Ageing Research, 4, 48-52.

Bock, O., \& Züll, A. (2013). Characteristics of Grasping Movements in a Laboratory and in an Everyday-Like Context. Human Movement Science, 32, 249-256. http://dx.doi.org/10.1016/j.humov.2012.12.009

Bock, O., Grigorova, V., \& Ilieva, M. (2013). Double-Step Adaptation of Saccadic Eye Movements Is Influenced by Priming with Age Stereotypies. Psychology, 4, 1014-1017. http://dx.doi.org/10.4236/psych.2013.412147

Branaghan, R. J., \& Gray, R. (2010). Nonconscious Activation of an Elderly Stereotype and Speed of Driving. Perceptual Motor Skills, 110, 580-592. http://dx.doi.org/10.2466/pms.110.2.580-592 
Hausdorff, J., Levy, B., \& Wie, J. (1999). The Power of Ageism on Physical Function of Older Persons: Reversibility of Age-Related Gait Changes. Journal of the American Geriatrics Society, 47, 1346-1349.

Hess, T. M., Hinson, J., \& Statham, J. (2004). Explicit and Implicit Stereotype Activation Effects on Memory: Do Age and Awareness Moderate the Impact of Priming? Psychology and Aging, 19, 495-505. http://dx.doi.org/10.1037/0882-7974.19.3.495

Horton, S., Baker, J., Pearce, G. W., \& Deakin, J. M. (2008). On the Malleability of Performance: Implications for Seniors. Journal of Applied Gerontology, 27, 446-465. http://dx.doi.org/10.1177/0733464808315291

Kite, M. E., Stockdale, G. D., Whitley Jr., B. E., \& Johnson, B. T. (2005). Attitudes toward Younger and Older Adults: An Updated Meta-Analytic Review. Journal of Social Issues, 61, 241-266. http://dx.doi.org/10.1111/j.1540-4560.2005.00404.x

Levy, B. (2000). Handwriting as a Reflection of Aging Self-Stereotypes. Journal of Geriatric Psychiatry, 33, 81-94.

Levy, B., Ashman, O., \& Dror, I. (2000). To Be or Not to Be: The Effects of Aging Stereotypes on the Will to Live. Omega (Westport), 40, 409-420.

Levy, B., Hausdorff, J. M., Hencke, R., \& Wei, J. Y. (2000). Reducing Cardiovascular Stress with Positive Self-Stereotypes of Aging. Journals of Gerontology Series B: Psychological Sciences and Social Sciences, 55, 205-213. http://dx.doi.org/10.1093/geronb/55.4.P205

Schwarzer, R., \& Jerusalem, M. (1995). Generalized Self-Efficacy Scale. In J. Weinman, S. Wright, \& M. Johnston (Eds.), Measures in Health Psychology: A User's Portfolio. Causal and Control Beliefs (pp. 35-37). Windsor: NFER-NELSON.

Wheeler, S. C., \& Petty, R. E. (2001). The Effects of Stereotype Activation on Behavior: A Review of Possible Mechanisms. Psychological Bulletin, 127, 797-826. http://dx.doi.org/10.1037/0033-2909.127.6.797

\section{Appendix}

Neutral words used in the scrambled sentence task:

1) FLIEGT; LILA; WEIT; DAS; FLUGZEUG

2) HOCH; WÄCHST; DIE; RASIERER; PFLANZE

3) GROß; TOR; DAS; IST; SCHNELL

4) MIETE; IST; WEITLÄUFIG; GARTEN; DER

5) DIE; HAARE; GESPRÄCHIG; LANG; SIND

6) SCHÖN; RIECHT; GUT; PARFUM; DAS

7) DAS; MUSIZIEREN; BLAUE; PFERD; AUTO

8) HIMMEL; GRÜN; IST; DER; BEWÖLKT

9) SIE; DAS; IST; GRÜN; BLATT

10) LAUT; DER; BELLT; HUND; AHORNBLATT

11) TIEF; IST; HUND; GRABEN; DER

12) VOGEL; LANG; IST; DIE; PAUSE

13) ROLLT; DER; KÄFIG; BALL; RUNDE

14) SCHLECHT; SAFT; SCHMECKT; FUCHS; DER

15) ERKLINGT; EINE; MELODIE; LEISE; IHR

16) TIEF; BLAU; DER; BRUNNEN; IST

17) AUSSERDEM; WEIN; BERAUSCHEND; IST; DER

18) GEHEIMNISVOLL; MACH; WALD; IST; DER

19) GROß; DIE; GESCHICHTE; FANTASTISCH; IST

20) FESSELND; KÖNIG; DAS; IST; BUCH 
Scientific Research Publishing (SCIRP) is one of the largest Open Access journal publishers. It is currently publishing more than 200 open access, online, peer-reviewed journals covering a wide range of academic disciplines. SCIRP serves the worldwide academic communities and contributes to the progress and application of science with its publication.

Other selected journals from SCIRP are listed as below. Submit your manuscript to us via either submit@scirp.org or Online Submission Portal.
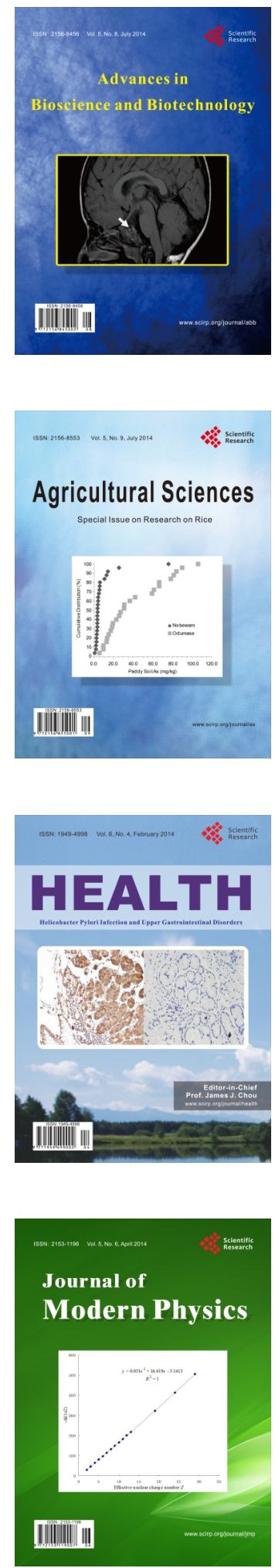
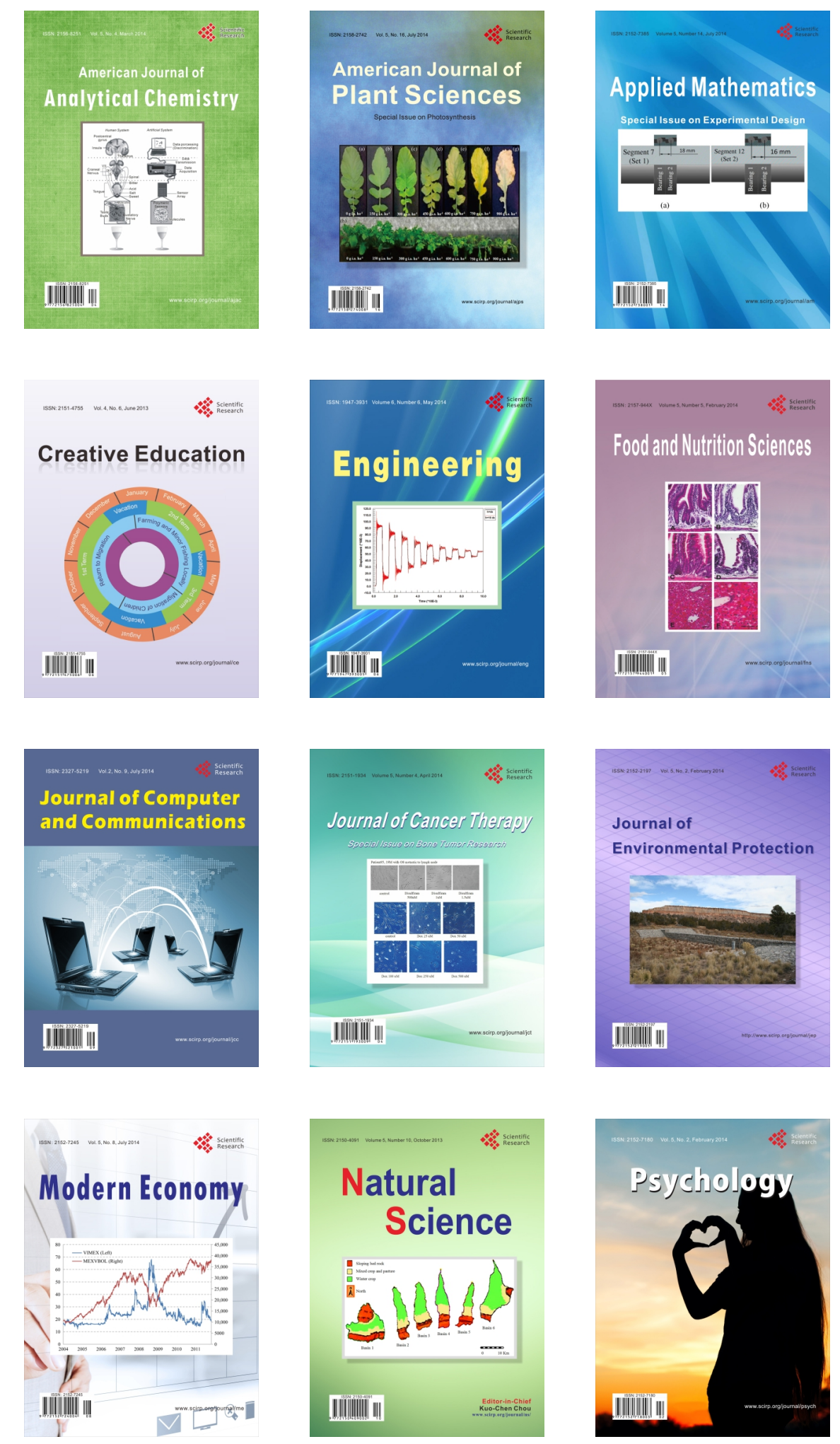